\title{
Home Oxygen Therapy Devices: Providing the Prescription
}

Long-term oxygen therapy (LTOT) is a common pharmacologic treatment for COPD and other lung diseases. Estimates from government records suggest that $>1$ million Medicare recipients receive oxygen at home at a cost exceeding \$2 billion dollars per year in the United States. ${ }^{1,2}$ The data supporting home LTOT in COPD is nearly four decades old, but these initial trials remain the scientific basis for prescription and treatment. ${ }^{3,4}$ In the ensuing 40 years, most additional trials have been limited by insufficient numbers and the evaluation of physiologic end points rather than important clinical outcomes. The use of oxygen in subjects with stable COPD and moderate hypoxemia failed to demonstrate any outcome benefits in a recent trial. ${ }^{5}$

Critical to the therapeutic benefit of LTOT is the prevention of hypoxemia in what might best be considered a dose response. Combining the 2 large trials supporting LTOT, a shorter duration of oxygen therapy (eg, nocturnal oxygen only) fails to confer a mortality benefit. We believe these data suggest that the maintenance of normoxemia and, just as important, preventing hypoxemia are the underlying physiologic manifestations that result in improved outcomes. ${ }^{3,4}$

The delivery of LTOT at home is complicated by the choice of devices, muddled by government regulations, difficult for durable medical equipment (DME) providers to achieve under the current reimbursement structure, confused by imprecise physician-prescribing practices, and most recently obfuscated by the competitive bidding process. ${ }^{6-8}$ Work by Jacobs et al and AlMutairi et $a^{6-8}$ have demonstrated that patients on home LTOT face innumerable challenges and are frequently dissatisfied with their home oxygen devices. Importantly, patients believe that "home" oxygen therapy devices are, in fact, intended to help them get out of the home! ${ }^{6}$ Patient mobility and device portability appear to go hand in hand with quality of life.

Mr Branson discloses relationships with Aerogen, Bayer, Philips, and Ventec Life Systems. He is also Editor-in Chief of RESPIRATORY CARE. Ms King is an employee of Mobile Medical Home Care and has a relationship with Ventec Life Systems. Mr Giordano has no conflicts to report.

Correspondence: Richard D Branson, Professor of Surgery, Division of Trauma \& Critical Care, University of Cincinnati, 231 Albert Sabin Way \#558, Cincinnati, OH 45267. E-mail: richard.branson@uc.edu.

DOI: $10.4187 /$ respcare.06850
Patients also express concern that portable devices may fail to provide sufficient oxygen to prevent hypoxemia. What if they're right? In this issue of RESPIRATORY CARE, Chen and colleagues ${ }^{9}$ evaluate portable oxygen concentrators (POCs) in both a model of the respiratory system and

See the Original Study on Page 117

using mathematical modeling. Their work builds on previous evaluations published in ResPIRATORY CARE. ${ }^{10,11}$ This work by Chen et $\mathrm{al}^{9}$ confirms the ability of pulse-dose oxygen to maximize oxygen delivery to alveolar units, maximizing efficiency. Their paper also highlights the variable function of POCs when set at the dimensionless numerical settings generally thought to equate to continuous flow oxygen flow (L/min).

Their paper brings to light concerns related to POCs, the prescription for oxygen, and confusion among caregivers and patients over what a POC setting represents. Chen et $\mathrm{al}^{9}$ demonstrate this, in that a group of concentrators can have settings or numerical values of 1-3 or 1-6. Through a number of assumptions, caregivers and patients often consider these pulse values as equivalent to a continuous flow (eg, a pulse setting of 3 is equivalent to $3 \mathrm{~L} / \mathrm{min}$ of continuous flow oxygen). These dimensionless numerical values are not only not equivalent to continuous flow in $\mathrm{L} / \mathrm{min}$, but on different devices the numerical settings provide widely disparate oxygen delivery.

Consider 3 fictional POC devices as shown in Table 1, similar to those studied by Chen et al. ${ }^{9}$ The size and weight of the devices indicate portability and perhaps the willingness of a patient to use the device during daily activities. Each device is capable of a maximum volume of oxygen generated per minute. Based on the volume of oxygen available and the patient's breathing frequency, the pulse volume, pulse frequency, or pulse oxygen purity may change. Oxygen purity represents the concentration of oxygen in the gas exiting the concentrator (typically 0.93 ). While device A may receive high marks for portability due to weight, the ability of the device to meet the patient's needs across a range of activity (ie, the goal of a POC) is limited. It is within the realm of possibility that failure to provide adequate oxygenation throughout the day might negate the mortality benefit seen with LTOT. The recent direct-to-consumer advertising of 


\section{EDITORIALS}

Table 1. Comparison of Portable Oxygen Concentrator Performance Under Changes in Patient Breathing Frequency and Demand Exceeding Oxygen Generation Capabilities

\begin{tabular}{|c|c|c|c|c|c|c|c|}
\hline \multirow{2}{*}{ Device } & \multirow{2}{*}{$\begin{array}{l}\text { Weight, } \\
\text { kg }\end{array}$} & \multirow{2}{*}{$\begin{array}{c}\text { Maximum } \mathrm{O}_{2} \\
\text { Generation, } \\
\mathrm{L} / \mathrm{min}\end{array}$} & \multirow{2}{*}{$\begin{array}{l}\text { Maximum Pulse } \\
\text { Volume at } \mathrm{f}=20 \\
\text { breaths } / \mathrm{min}, \mathrm{mL}\end{array}$} & \multicolumn{3}{|c|}{$\begin{array}{l}\text { POC Numerical } \\
\text { Setting }\end{array}$} & \multirow{2}{*}{$\begin{array}{l}\text { POC Strategy in Response to } \\
\text { Hyperpnea (eg, exercise: } \mathrm{f}=30 \text { breaths } / \mathrm{min} \text { ) }\end{array}$} \\
\hline & & & & 1 & 2 & 3 & \\
\hline A & 2 & 0.5 & 25 & 8.3 & 16.6 & 25 & Deliver a consistent oxygen purity every $2-3$ breaths \\
\hline B & 4 & 1.5 & 75 & 25 & 50 & 75 & Deliver a reduced pulse volume at a consistent oxygen purity \\
\hline $\mathrm{C}$ & 8 & 3.0 & 150 & 50 & 100 & 150 & Deliver a consistent pulse volume at a reduced oxygen purity \\
\hline
\end{tabular}

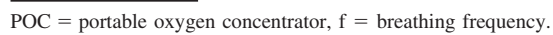
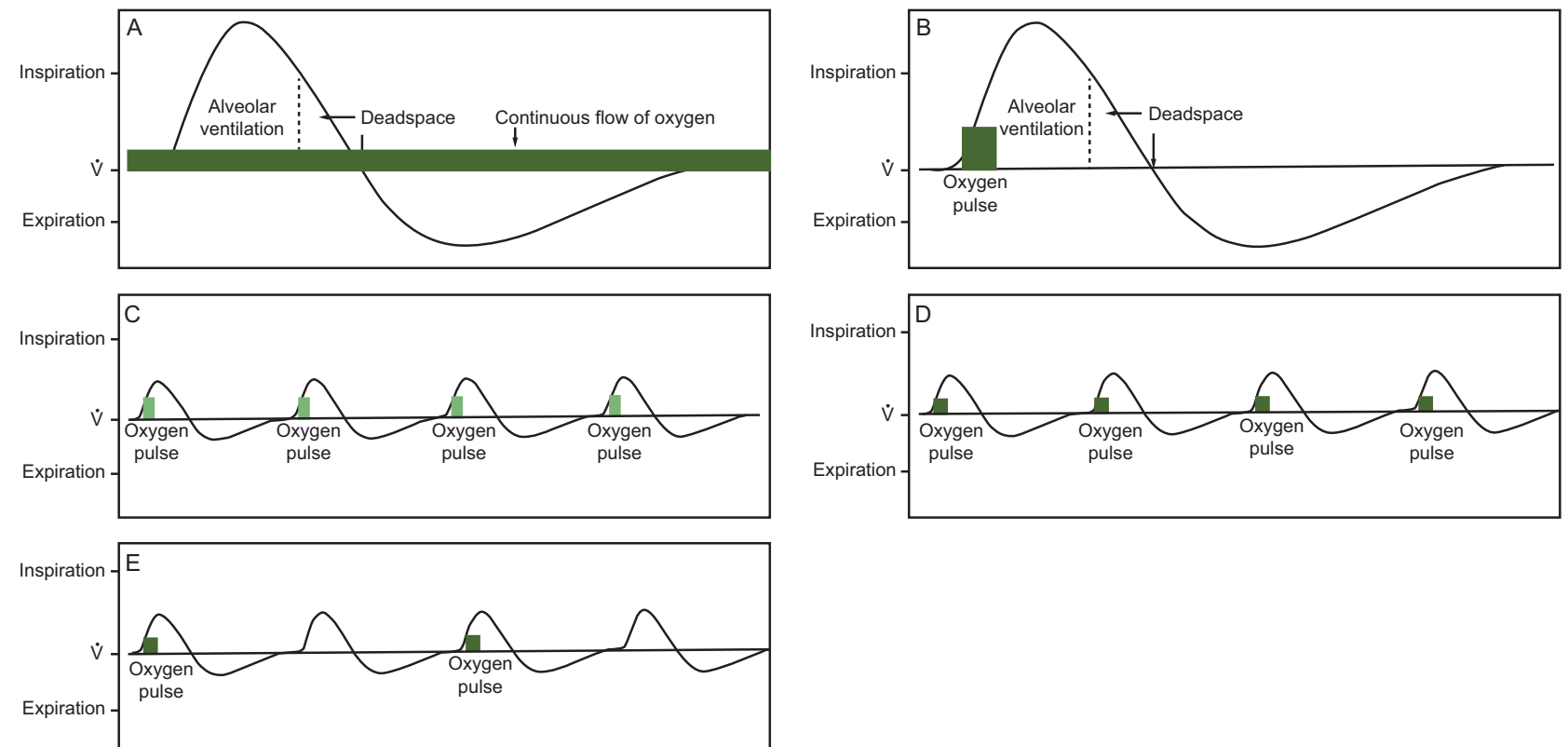

Fig. 1. A: A normal breath with continuous flow oxygen delivery. Note the waste of oxygen during expiration. B: A pulse dose breath from a portable oxygen concentrator (POC) (93\% oxygen purity) at the desired pulse volume. Delivered early in the breath, oxygen is directed to gas-exchange units and no oxygen is wasted during exhalation. C: Increased breathing frequency exceeds the oxygen-generation capability of the POC per minute. In this example, the pulse volume remains the same with every breath, but the oxygen purity falls (lighter green) to $85 \%$. D: Increased breathing frequency exceeds the oxygen-generation capability of the POC per minute. In this example, the pulse volume decreases, but the oxygen purity (93\%) remains the same. E: Increased breathing frequency exceeds the oxygen-generation capability of the POC per minute. In this example, the pulse volume and oxygen purity remains the same (93\%), but the POC only delivers oxygen every second or third breath.

POCs represents another paradigm change. We caution here that patients can buy devices without oversight by a respiratory therapist who can assure that the device meets their oxygenation needs. A device may be chosen on the basis of appearance and size, not functionality and ability to meet the desired goals. No other drug is delivered in this manner. Figure 1 demonstrates strategies used by POCs when the patient's breathing frequency exceeds the oxygen generation capabilities of the device.

How then, can these problems be addressed? Rather than use dimensionless numerical values, POC manufacturers could list the volume of oxygen delivered at each setting. This would allow consumers an opportunity to compare device capability. However, we must admit that even these data might be confusing to patients, prescribing physicians, and DME providers. The most important value is the total volume of oxygen generated per minute, because this determines performance characteristics with variable patient breathing frequency.

LTOT at home begins with qualification of the patient under Centers for Medicare and Medicaid Services (CMS) rules and the oxygen prescription. Currently, CMS uses the antiquated method of flow to pay for LTOT and requires the physician write a flow prescription (in $\mathrm{L} / \mathrm{min}$ ). As Chen et al ${ }^{9}$ and others have shown, the translation from flow in $\mathrm{L} / \mathrm{min}$ to pulse dose is fraught with potential errors. ${ }^{9-11}$ We believe the 
seminal change to home LTOT begins with the prescription. Rather than a flow, the prescription should target a desired oxygen saturation $\left(\mathrm{S}_{\mathrm{pO}_{2}}\right)$ range monitored by pulse oximetry. Theoretically, this would allow the optimization of oxygen therapy, providing the maximum benefit for the money. This might also allow the use of automated control to maintain $\mathrm{S}_{\mathrm{pO}_{2}}{ }^{12}$ Pulse oximetery is ubiquitous, but it is not reimbursed by CMS. This is a problem that needs to be addressed. Importantly, assessment of $\mathrm{S}_{\mathrm{pO}_{2}}$ and POC adequacy should be accomplished by a respiratory therapist (not the person delivering oxygen or DME supplies to the patient's home). LTOT is a significant expense to the health care system, but the value proposition of insufficient oxygen delivery coupled with generally nonexistent respiratory therapist oversight potentially provides no benefit for the dollars invested.

The competitive bidding process appears to have reduced the options for home LTOT patients, primarily by eliminating the availability of liquid oxygen systems. ${ }^{6}$ For some patients requiring significant flow $(>3 \mathrm{~L} / \mathrm{min})$ at rest, liquid oxygen is the best option for meeting patient demands during activity and maximizing day excursions. ${ }^{6}$ Even here, as always, the devil is in the details. Liquid oxygen provides an ideal solution for patients who require higher flows for day trips. However, on longer trips, the evaporation of liquid oxygen represents a potential disadvantage. There may be efficiencies to be had with new technology in POC devices. We await these advancements. In the meantime, we encourage users and providers to call for an approach to home LTOT that is patientfocused, not cost-focused. This starts with the oxygen prescription and maximizing the mortality benefit of LTOT by matching devices to patient needs. The follow-up step should be the evaluation of the device's ability meet patient needs by a licensed health care provider to guide device selection and use. Oxygen therapy requirements of patients and meeting the prescription with oxygen therapy devices is complicated. The solution requires forethought and appreciation of the nuances in device operation.

Richard D Branson

Editor-in-Chief, Respiratory CARE Irving, Texas

University of Cincinnati Cincinnati, Ohio

Angela King

Mobile Medical Homecare Leo, Indiana
Sam P Giordano

Publisher Emeritus, Respiratory Care Chairman, U.S. COPD Coalition

Carrollton, Texas

\section{REFERENCES}

1. Croxton TL, Bailey WC. Long-term oxygen treatment in chronic obstructive pulmonary disease: recommendations for future research: an NHLBI workshop report. Am J Respir Crit Care Med 2006; 174(4):373-378.

2. Doherty DE, Petty TL, Bailey W, Carlin B, Casaburi R, Christopher $\mathrm{K}$, et al. Recommendations of the 6th long-term oxygen therapy consensus conference. Respir Care 2006;51(5):519-525.

3. Nocturnal Oxygen Therapy Trial Group. Continuous or nocturnal oxygen therapy in hypoxemic chronic obstructive lung disease: a clinical trial. Ann Intern Med 1980;93(3):391-398.

4. Report of the Medical Research Council Working Party. Long-term domiciliary oxygen therapy in chronic hypoxic cor pulmonale complicating chronic bronchitis and emphysema. Lancet 1981;1(8222):681686.

5. Long-Term Oxygen Treatment Trial Research Group; Albert RK, Au DH, Blackford AL, Casaburi R, Cooper JA Jr, Criner GH, et al. A randomized trial of long-term oxygen for COPD with moderate desaturation. N Engl J Med 2016;375(17):1617-1627.

6. Jacobs SS, Lederer DJ, Garvey CM, Hernandez C, Lindell KO, McLaughlin S, et al. Optimizing home oxygen therapy. An Official American Thoracic Society Workshop Report. Ann Am Thorac Soc 2018;15(12):1369-1381.

7. AlMutairi HJ, Mussa CC, Lambert CT, Vines DL, Strickland SL. Perspectives from COPD subjects on portable long-term oxygen therapy devices. Respir Care 2018;63(11):1321-1330.

8. Jacobs SS, Lindell KO, Collins EG, Garvey CM, Hernandez C, McLaughlin S, et al. Patient perceptions of the adequacy of supplemental oxygen therapy: results of the American Thoracic Society nursing assembly oxygen working group survey. Ann Am Thorac Soc 2018;15(1):24-32.

9. Chen J, Katz I, Pichelin M, Zhu K, Callibotte G, Finlay W, Martin A. In vitro-in silico comparison of pulsed oxygen delivery from portable oxygen concentrators versus continuous flow oxygen delivery. Respir Care 2019;64(2):117-129.

10. Zhou S, Chatburn RL. Effect of the anatomic reservoir on low-flow oxygen delivery via nasal cannula: constant flow versus pulse flow with portable oxygen concentrator. Respir Care 2014;59(8):11991209.

11. Chatburn RL, Williams TJ. Performance comparison of 4 portable oxygen concentrators. Respir Care. 2010 Apr;55(4):433-442. Erratum in: Respir Care 2010;55(6):789.

12. Lellouche F, L'Her E, Bouchard PA, Brouillard C, Maltais F. Automatic oxygen titration during walking in subjects with COPD: a randomized crossover, controlled study. Respir Care 2016;61(11):1456-1464. 